\title{
Willingness to get the COVID-19 vaccine among patients with rheumatic diseases, healthcare workers and general population in Turkey: a web-based survey
}

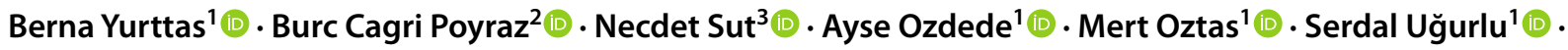 \\ Fehmi Tabak ${ }^{4}\left[\right.$ Vedat Hamuryudan $^{1}{ }^{10} \cdot$ Emire Seyahi $^{1}{ }^{10}$
}

Received: 12 February 2021 / Accepted: 9 March 2021 / Published online: 29 March 2021

(c) The Author(s), under exclusive licence to Springer-Verlag GmbH Germany, part of Springer Nature 2021

\begin{abstract}
Objectives Vaccination against COVID-19 emerges as an effective strategy for combating the pandemic. While many of our patients with rheumatic diseases (RD) wonder whether it is safe to get the vaccine, vaccine hesitancy is rising among the general population. We assessed the willingness to get vaccination and its probable predictors among patients with RD compared to healthcare workers and a sample from the general population.

Methods We conducted a web-based questionnaire survey in a cross-sectional design in 3 groups of participants just before the mass vaccination program in Istanbul, Turkey. The questionnaire sought socio-demographic variables, COVID-19 related risk factors, willingness to get vaccination, and concerns and thoughts about vaccine. COVID-19 anxiety scale (CAS) was also evaluated.

Results We studied in total 732 patients with RD (Group 1), 763 individuals representing general population (Group 2) and 320 hospital workers (Group 3). Dysfunctional anxiety related to COVID-19 was found in 4.9\%, 3.8\% and 4.1\%, in Group 1, 2 and 3, respectively. Of the patients with RD, 29.2\% were willing to be vaccinated, $19.0 \%$ were unwilling and $51.8 \%$ were undecided. These were somewhat similar among the general population (yes: $34.6 \%$, no: $23.3 \%$ and unsure: $42.1 \%$ ), with significantly less undecided individuals $(\mathrm{p}<0.001)$. On the other hand, hospital workers were significantly more willing (yes: $52.5 \%$, no: $20.9 \%$ and unsure: $26.6 \%)(p<0.001)$. Main concerns were probable side effects, unknown scientific results and having no trust. Being male, older age, working in a hospital, not having contracted COVID-19 and high scores on CAS were found to be independently associated with willingness.

Conclusions The low rate of vaccine acceptance among patients with RD, as well as general population sampling is worrying. Healthcare policies should aim to implement communication, promote confidence and increase demand for COVID-19 vaccine.
\end{abstract}

Keywords Vaccination · Willingness $\cdot$ Hesitancy $\cdot$ COVID-19 $\cdot$ Rheumatic diseases $\cdot$ Healthcare workers $\cdot$ Web-based survey $\cdot$ COVID-19 associated anxiety

\section{Introduction}

Since it emerged in December 2019, the Coronavirus disease-2019 (COVID-19) pandemic has been responsible for more than 2.2 million deaths worldwide [1]. Vaccination of a large portion of the population is considered essential in order to establish herd immunity [2]. Multiple potential

Emire Seyahi

eseyahi@yahoo.com; eseyahi@yahoo.com

Extended author information available on the last page of the article vaccines against COVID-19 have been developed at an unprecedented speed [3] and as of December 2020, mass vaccination programs were started in many countries.

The first case of COVID-19 in Turkey was officially confirmed on March 11 2020. As of 15 February 2021, Turkey, where over 83 million people reside, has officially reported 2.594.128 confirmed cases and 27.562 deaths due to COVID-19 [4]. While conducting its own vaccine research, the country has made an agreement with China to use inactivated vaccine candidate, 'CoronaVac' produced by biopharmaceutical company Sinovac, which is still in the 3rd trial phase [5-9]. As of January 13, based on the 
unpublished results from the trials in Indonesia and Brazil, as well as on "interim analyses", Medicines and Medical Devices Agency of Turkey granted emergency use authorization (EUA) to Sinovac COVID-19 vaccine [7-9]. On the following day (January 14), mass vaccination campaign started with healthcare workers along with people aged 65 and over.

In recent months, many of our patients having a rheumatic disease (RD) called us for permission to get vaccination, while some expressed their concerns about the efficacy and safety issues. Moreover, the general public also seemed to be somewhat hesitant about accepting a vaccine. We, therefore, did a cross-sectional survey of patients with RD, healthcare workers whom we assumed would be willing to get the vaccine and a sample from the general population. The purpose of the study was to estimate COVID-19 vaccine acceptance and to evaluate attitudes and thoughts toward vaccination just before the vaccination program took place in Turkey.

\section{Patients and methods}

A web-based survey was conducted in a cross-sectional design using the Survey Monkey software (SurveyMonkey, San Mateo, CA, USA) and sent out to the participants via WhatsApp link. The study groups consisted of patients with $\mathrm{RD}$ (Group 1), general population (Group 2) and healthcare workers (Group 3). The online survey (supplementary material) was designed and executed as suggested by Gaur et al. [10]. The electronic questionnaire has been tested in 22 individuals among the hospital workers before fielding it. After this pilot testing these responses were discarded. Duplicate entries were not allowed. Incomplete questionnaires were also analyzed. The survey included 27 questions in total. The questions were related to socio-demographic characteristics [five questions], social media use [one question], risk factors for COVID-19 [four questions], previous diagnosis or death due to COVID-19 among the household or close circle [three questions], willingness to get vaccination [three questions], associated concerns or thoughts about vaccination [four questions] and COVID-19 associated anxiety [five questions]. Participants were also asked whether they have been previously diagnosed with a comorbid disease (such as cardiovascular disease, chronic lung disease, hypertension, diabetes mellitus or else) (one question) and a psychiatric disorder (one question). Patients with RD were additionally asked for their specific diagnosis, disease duration and drugs used for the last 3 months (three questions).

COVID-19 related anxiety was assessed using the COVID-19 anxiety scale (CAS) [11] validated in Turkish [12]. The CAS is a 5-item mental health screener developed to determine probable cases of dysfunctional anxiety associated with the COVID-19 crisis [11-13]. Each item was scored from 0 to 4 points, making a total score ranging between 0 and 20. Additionally, a cut-off point of $\geq 9$ has been shown to have a good accuracy in diagnosing dysfunctional anxiety (90\% sensitivity and $85 \%$ specificity) [13].

\section{Identification and selection of the study population}

\section{Group 1: Patients with RD}

We identified six subgroups of rheumatic diseases: 1) rheumatoid arthritis (RA); 2) connective tissue disease (CTD) which included systemic lupus erythematosus, systemic sclerosis and primary Sjögren syndrome; 3) spondylarthropathies (SpA); 4) Behçet's syndrome (BS); 5) familial Mediterranean fever (FMF); 6) vasculitides which included several types of large and small-vessel vasculitis. Patients who were examined within the last six months in our outpatient clinic were identified and 250 patients from each subgroup were consecutively selected as the target study population. Phone numbers of the patients were retrieved mainly from the personal patient database of one of the authors (E.S) and also from the archives of rheumatology outpatient clinic of Cerrahpasa Medical Faculty. Of these 1500 patients, 732 (258 M/ 474 F) (48.8\%) responded.

\section{Group 2: General population sample}

People who are not hospital workers and who are not registered patients with RD constituted the general population. Snowball technique was used to reach the population and a total of 763 individuals $(258 \mathrm{M} / 505 \mathrm{~F})$ responded. Response rate could not be calculated.

\section{Group 3: Healthcare workers}

Web-based questionnaire was sent to the staff of our university hospital (400 physicians, 800 nurses and 200 medical and non-medical personnel). Of these 1400 hospital workers, $320(88 \mathrm{M} / 232 \mathrm{~F})(22.9 \%)$ responded. These were physicians $(n=152 ; 56 \mathrm{M} / 96 \mathrm{~F})$, nurses $(n=113 ; 10 \mathrm{M} / 103 \mathrm{~F})$ and medical or non-medical personnel $(n=55 ; 22 \mathrm{M} / 33 \mathrm{~F})$.

\section{Ethical statement}

The survey was anonymous, voluntary and ran between 04 and 13 January, 2021. It was approved by the Ministry of Health (2021-01-04T16_41_30). The study was also approved by the Ethics Committee of Istanbul University-Cerrahpasa, Cerrahpasa Medical Faculty (10.03.2021-49044). 


\section{Statistical analysis}

Normality distribution of the numeric variables was tested by the Shapiro Wilk test. Numeric results were expressed as mean \pm standard deviation and categorical results were expressed as n (\%). Kruskal Wallis test was used for comparison of non-normally distributed variables and then Dunn's test with Bonferroni correction was used for multiple comparisons when the significantly meaningful difference was obtained. Categorical variables were compared using Pearson's chi-square test. Reliability of the CAS was assessed using Cronbach's alpha coefficient. Thirteen probable variables (group, age, gender, education, the length of social media use, comorbidity, leaving the house for work quite often, previous diagnosis of COVID-19 in the participant itself or someone in the close circle, death due to COVID-19 among the household or in the close circle, anxiety associated with COVID-19, psychiatric disease, and household size) that could affect willingness to get COVID-19 vaccination were defined. We used the first univariate analysis to investigate whether these variables were associated with reluctance (No vs Yes). Those who responded as 'unsure' were excluded from this analysis. Then, nine variables whose $p$ values were found $<0.15$ in the univariate analysis were included in the multivariate logistic regression analysis with Enter method. IBM SPSS Statistics for Windows, v.20.0 (IBM Corp., Armonk, NY, USA) was used in the statistical analysis. A $p$ value of less than 0.05 was accepted as statistical significance.

\section{Results}

In total, we studied $732(258 \mathrm{M} / 474 \mathrm{~F})$ patients with RD (Group 1), $763(258 \mathrm{M} / 50 \mathrm{~F})$ individuals representing the general population (Group 2) and $320(88 \mathrm{M} / 232 \mathrm{~F})$ healthcare workers (Group 3).

Patients with RD were categorized in six subgroups: 1) RA ( $n=84 ; 15 \mathrm{M} / 69 \mathrm{~F}) ; 2)$ CTD $(n=122 ; 10 \mathrm{M} / 112 \mathrm{~F})$; 3) $\mathrm{SpA}(n=114 ; 62 \mathrm{M} / 52 \mathrm{~F})$; 4) $\mathrm{BS}(n=189 ; 115 \mathrm{M} / 74 \mathrm{~F})$; 5) $\mathrm{FMF}(n=131 ; 43 \mathrm{M} / 88 \mathrm{~F})$; 6) Vasculitides $(n=92$; $13 \mathrm{M} / 79 \mathrm{~F})$. The mean disease duration of the patients was calculated as $13.5 \pm 10.1$ years. A total of 670 (92\%) patients were using one or more of the following such as biological disease-modifying anti-rheumatic drugs (DMARDs) $(n=259,39 \%)$, non-biological DMARDs $(n=270,40 \%)$, prednisolone $(n=198,30 \%)$, hydroxychloroquine $(n=136$, $20 \%)$ and colchicine $(n=224,33 \%)$ at the time of the survey. Distribution of the drugs by diagnosis were as follows:

(a) Biological DMARDS (RA: $n=34$; CTD: $n=15$; SpA: $n=73$; BS: $n=54$; FMF: $n=37$; Vasculitis: $n=46$ ) (b) Non-biological DMARD's (RA: $n=49$; CTD: $n=50$; SpA: $n=35$; BS: $n=78$; FMF: $n=10$; Vasculitis: $n=48)$

(c) Prednisolone (RA: $n=43$; CTD: $n=56$; SpA: $n=14$; BS: $n=31$; FMF: $n=9$; Vasculitis: $n=45$ )

(d) Hydroxychloroquine (RA: $n=30$; CTD: $n=94$; SpA: $n=3$; BS: $n=2$; FMF: $n=5$; Vasculitis: $n=2$ )

(e) Colchicine (RA: $n=2$; CTD: $n=0$; SpA: $n=1$; BS: $n=104$; FMF: $n=117$; Vasculitis: $n=0$ )

\section{Socio-demographic characteristics (Table 1)}

Respondents were mostly female in all study groups while being significantly more in Group 3. Patients with RD were significantly older, less educated and had a more crowded household compared to both control groups. TV and social media were the common sources of information about vaccination for all groups. Additionally, institutional declarations and medical literature were among the frequently used sources for hospital workers. Patients with RD spent the least amount of time using social media, whereas the general population spent the highest amount of time.

\section{COVID-19 Anxiety scale (Table 1)}

A total $712(252 \mathrm{M} / 460 \mathrm{~F})$ patients with $\mathrm{RD}, 718$ (240M/478F) individuals from the general population sample and $310(83 \mathrm{M} / 227 \mathrm{~F})$ healthcare workers completely fulfilled the scale. Cronbach's alpha coefficient was calculated as 0.827 indicating high internal consistency. The CAS scores were comparable among the study groups. The frequency of dysfunctional anxiety was less than 4.9, 3.8 and $4.1 \%$ in Group 1, 2 and 3, respectively. Females had significantly higher scores and a higher frequency of dysfunctional anxiety compared to males in each study group (data not shown).

\section{Frequency of COVID-19 diagnosis and its potential risk factors (Table 2)}

The frequency of COVID-19 diagnosis both in the participant and in the household or close circle was significantly the highest among the hospital workers. As expected, hospital workers were the group most likely to leave the house frequently for work during the pandemic. The group of the general population was the least likely group to contract COVID-19 as well as the least likely group to go out for work. On the other hand, the frequency of death due to COVID-19 among the household or close circle was comparable across the study groups. The frequency of any comorbid disease as well as the psychiatric disease was significantly higher only among the patients with RD. 
Table 1 Socio-demographic variables and resources of information about vaccination

\begin{tabular}{|c|c|c|c|c|}
\hline & $\begin{array}{l}\text { Group } 1 \\
\text { Patients with RD }(n=732)\end{array}$ & $\begin{array}{l}\text { Group } 2 \\
\text { General popula- } \\
\text { tion }(n=763)\end{array}$ & $\begin{array}{l}\text { Group } 3 \\
\text { Healthcare workers } \\
(n=320)\end{array}$ & $P$ \\
\hline Male/Female, $n$ (ratio) & $258 / 474(0.54)$ & $258 / 505(0.51)$ & $88 / 232(0.38)$ & $0.045 \dagger \S$ \\
\hline Age, mean $\pm S D$, years & $42.8 \pm 11.6$ & $40.8 \pm 12.0$ & $37.0 \pm 10.0$ & $<0.001 *+\S$ \\
\hline Primary/middle school education, $n(\%)$ & $225(30.7)$ & $28(3.7)$ & $6(1.9)$ & $<0.001 * \dagger$ \\
\hline Household $(\geq 4), n(\%)$ & $357(48.8)$ & $252(33.2)$ & $116(35.9)$ & $<0.001 * \dagger$ \\
\hline Need to leave the house for work, quite often, $n(\%)$ & $264(36.1)$ & $210(27.5)$ & $283(88.4)$ & $<0.001 * \dagger \S$ \\
\hline \multicolumn{5}{|l|}{ Source of information related to vaccination, $n(\%)$} \\
\hline I have no information & $34(4.6)$ & $20(2.6)$ & $9(2.8)$ & 0.079 \\
\hline Newspaper & $120(16.4)$ & $162(21.2)$ & $57(17.8)$ & $0.05 * \S$ \\
\hline TV & $533(72.8)$ & $486(63.7)$ & $138(43.1)$ & $<0.001 * \dagger \S$ \\
\hline Social media & $425(58.1)$ & $547(71.7)$ & $171(53.4)$ & $<0.001 *+\S$ \\
\hline Institution & $26(3.6)$ & $50(6.6)$ & $168(52.5)$ & $<0.001 *+\S$ \\
\hline Friends & $75(10.2)$ & $116(15.2)$ & $77(24.1)$ & $<0.001 *+\S$ \\
\hline Medical literature & $8(1.1)$ & $22(2.9)$ & $39(12.2)$ & $<0.001 \uparrow \S$ \\
\hline$\leq 1$ h daily spent using social media & $270(36.9)$ & $192(25.2)$ & $100(31.3)$ & $<0.001 * \dagger \S$ \\
\hline \multicolumn{5}{|l|}{ COVID-19 anxiety scale } \\
\hline Total score, mean $\pm \mathrm{SD}$ & $1.62 \pm 3.03$ & $1.55 \pm 2.71$ & $1.81 \pm 2.64$ & 0.389 \\
\hline Cut off value of $\geq 9, n(\%)$ & $36(4.9)$ & $11(3.8)$ & $18(4.1)$ & 0.553 \\
\hline
\end{tabular}

$P^{*}$ :Group 1 vs Group 2, †: Group 1 vs Group 3, §: Group 2 vs Group 3

Table 2 COVID-19 diagnosis and risk factors for COVID-19

\begin{tabular}{|c|c|c|c|c|}
\hline & $\begin{array}{l}\text { Group } 1 \\
\text { Patients with RD } \\
(n=732)\end{array}$ & $\begin{array}{l}\text { Group } 2 \\
\text { General popula- } \\
\text { tion }(n=763)\end{array}$ & $\begin{array}{l}\text { Group } 3 \\
\text { Healthcare work- } \\
\text { ers }(n=320)\end{array}$ & $P$ \\
\hline $\begin{array}{l}\text { COVID-19 diagnosis in the participant, } n(\%) \\
\text { Yes } \\
\text { No } \\
\text { Unsure }\end{array}$ & $\begin{array}{l}104(14.2) \\
617(84.3) \\
11(1.5)\end{array}$ & $\begin{array}{l}70(9.2) \\
687(90.0) \\
6(0.8)\end{array}$ & $\begin{array}{l}69(21.6) \\
248(77.5) \\
3(0.9)\end{array}$ & $<0.001 * \dagger \S$ \\
\hline $\begin{array}{l}\text { COVID-19 diagnosis among the household or close circle, } n(\%) \\
\text { Yes } \\
\text { No } \\
\text { Unsure }\end{array}$ & $\begin{array}{l}460(62.8) \\
254(34.7) \\
18(2.5)\end{array}$ & $\begin{array}{l}435(57.0) \\
317(41.5) \\
11(1.4)\end{array}$ & $\begin{array}{l}244(76.3) \\
76(23.8) \\
0\end{array}$ & $<0.001 * \dagger \S$ \\
\hline Death due to COVID-19 among the household or close circle, $n(\%)$ & $198(27.0)$ & $217(28.4)$ & $96(30.0)$ & 0.603 \\
\hline Presence of any comorbid diseases, $n(\%)$ & $304(41.5)$ & $181(23.7)$ & $67(20.9)$ & $<0.001 * \dagger$ \\
\hline $\begin{array}{l}\text { History of psychiatric disorders or psychiatric drug use for at least } \\
\text { three months, } n(\%)\end{array}$ & $177(24.2)$ & $110(14.4)$ & $51(15.9)$ & $<0.001 * \dagger$ \\
\hline
\end{tabular}

$P *$ Group 1 vs Group 2, †: Group 1 vs Group 3, §: Group 2 vs Group 3

\section{Perception towards vaccination (Tables 3, 4 and 5)}

Of the patients with RD, $29.2 \%$ were willing to get vaccinated, $19.0 \%$ were unwilling and $51.8 \%$ were undecided (Table 3). There were significantly more undecided individuals among patients with RD compared to the general population sample $(51.8 \%$ versus $42.1 \%, p<0.001)$. Besides that, those who accept and who do not accept vaccination were balanced among patients with RD and the general population (yes: $29.2 \%$ versus $34.6 \%$ and no: $19.0 \%$ versus $23.3 \%$ ).
Healthcare workers were the most willing (yes: $52.5 \%$, no: $20.9 \%$ and unsure: $26.6 \%)(p<0.001)$. Moreover, healthcare workers were more likely 'to not consider vaccination if they were to be infected with COVID-19 recently (yes: 19.3\%, no: $59.1 \%$ and unsure: $21.6 \%)(p<0.001)$ and in addition thought significantly more than other groups that vaccination should be mandatory (yes: $35.3 \%$, no: $42.5 \%$ and unsure: $22.2 \%)(p=0.003)$. Only $29.5 \%$ of the patients with RD and $27.1 \%$ of the general population thought that vaccination should be obligatory. As seen in Table 3, among healthcare 
Table 3 Perception towards COVID-19 vaccination

\begin{tabular}{|c|c|c|c|c|c|c|}
\hline & \multirow{2}{*}{$\begin{array}{l}\text { Group } 1 \\
\text { Patients with } \\
\mathrm{RD}(n=732)\end{array}$} & \multirow{2}{*}{$\begin{array}{l}\text { Group } 2 \\
\text { General } \\
\text { population } \\
(n=763)\end{array}$} & \multicolumn{3}{|c|}{$\begin{array}{l}\text { Group } 3 \\
\text { Healthcare workers }\end{array}$} & \multirow[t]{2}{*}{$P$} \\
\hline & & & Total $(n=320)$ & Physicians $(n=152)$ & $\begin{array}{l}\text { Nurses and medical/ } \\
\text { non-medical personnel } \\
(n=168)\end{array}$ & \\
\hline $\begin{array}{l}\text { Willingness to get vaccination, } \\
n(\%) \\
\text { Yes } \\
\text { No } \\
\text { Unsure }\end{array}$ & $\begin{array}{l}214(29.2) \\
139(19.0) \\
379(51.8)\end{array}$ & $\begin{array}{l}264(34.6) \\
178(23.3) \\
321(42.1)\end{array}$ & $\begin{array}{l}168(52.5) \\
67(20.9) \\
85(26.6)\end{array}$ & $\begin{array}{l}104(68.4) \\
17(11.2) \\
31(20.4)\end{array}$ & $\begin{array}{l}64(38.1) \\
50(29.8) \\
54(32.1)\end{array}$ & $<0.001 *+\S$ \\
\hline $\begin{array}{l}\text { Would you consider vac- } \\
\text { cination if you have been } \\
\text { previously diagnosed with } \\
\text { COVID-19? } n(\%) \\
\text { Yes } \\
\text { No } \\
\text { Unsure }\end{array}$ & $\begin{array}{l}143(20.7) \\
237(34.3) \\
310(44.9)\end{array}$ & $\begin{array}{l}169(23.8) \\
273(38.5) \\
268(37.7)\end{array}$ & $\begin{array}{l}58(19.3) \\
178(59.1) \\
65(21.6)\end{array}$ & $\begin{array}{l}30(21.3) \\
90(63.8) \\
21(14.9)\end{array}$ & $\begin{array}{l}28(17.5) \\
88(55.0) \\
44(27.5)\end{array}$ & $<0.001 * \S$ \\
\hline $\begin{array}{l}\text { Do you think that vaccination } \\
\text { should be mandatory? } n(\%) \\
\text { Yes } \\
\text { No } \\
\text { Unsure }\end{array}$ & $\begin{array}{l}216(29.5) \\
277(37.8) \\
239(32.7)\end{array}$ & $\begin{array}{l}207(27.1) \\
331(43.4) \\
225(29.5)\end{array}$ & $\begin{array}{l}113(35.3) \\
136(42.5) \\
71(22.2)\end{array}$ & $\begin{array}{l}66(43.4) \\
59(38.8) \\
27(17.8)\end{array}$ & $\begin{array}{l}47(28.0) \\
77(45.8) \\
44(26.2)\end{array}$ & $0.003 \dagger \S$ \\
\hline $\begin{array}{l}\text { Was there any change in your } \\
\text { point of view towards vac- } \\
\text { cination in general recently? } \\
n(\%) \\
\text { None } \\
\text { Yes in a positive way } \\
\text { Yes in a negative way }\end{array}$ & $\begin{array}{l}510(69.7) \\
111(15.2) \\
111(15.2)\end{array}$ & $\begin{array}{l}534(70.0) \\
109(14.3) \\
120(15.0)\end{array}$ & $\begin{array}{l}224(70.0) \\
55(17.2) \\
41(12.8)\end{array}$ & $\begin{array}{l}113(74.3) \\
28(18.4) \\
11(7.2)\end{array}$ & $\begin{array}{l}111(66.1) \\
27(16.1) \\
30(17.9)\end{array}$ & 0.633 \\
\hline
\end{tabular}

$P *$ Group 1 vs Group 2, †: Group 1 vs Group 3, §: Group 2 vs Group 3

Table 4 Which country's vaccine would you prefer, If it was to be available ( $n \%)$

\begin{tabular}{lcccc}
\hline & $\begin{array}{l}\text { Group 1 } \\
\text { Patients with RD } \\
(n=732)\end{array}$ & $\begin{array}{l}\text { Group 2 } \\
\text { General population } \\
(n=763)\end{array}$ & $\begin{array}{l}\text { Group 3 } \\
\text { Healthcare workers } \\
(n=320)\end{array}$ & $P$ \\
\hline USA/Germany & $260(35.5)$ & $357(46.8)$ & $155(48.4)$ & $<0.001^{* \dagger}$ \\
Turkey & $339(46.3)$ & $198(26.0)$ & $52(16.3)$ & $<0.001^{* \dagger \S}$ \\
China & $44(6.0)$ & $45(5.9)$ & $51(15.9)$ & $<0.001 \dagger \S$ \\
United Kingdom & $27(3.7)$ & $51(6.7)$ & $22(6.9)$ & $0.020^{* \dagger}$ \\
Russia & $7(1.0)$ & $13(1.3)$ & $3(0.9)$ & 0.367 \\
I have no idea & $128(17.5)$ & $159(20.8)$ & $52(16.3)$ & 0.118 \\
\hline
\end{tabular}

$P^{*}$ Group 1 vs Group 2, †: Group 1 vs Group 3, §: Group 2 vs Group 3 workers vaccine intention differed significantly according to the professional role. $68.4 \%$ of physicians whereas $38.1 \%$ of the nurses and hospital personnel agreed that they would take the vaccine, $(p<0.001)$. It was noted that $11.2 \%$ of the physicians compared to $29.8 \%$ of the nurses and hospital personnel were unwilling. Similarly, $43.4 \%$ of the physicians whereas $28.0 \%$ of the nurses and personnel thought that vaccination should be mandatory $(p<0.0001)$. The opinion towards vaccination, in general, seemed to not have changed recently in the majority of the respondents in all study groups $(p=0.633)$.

As shown in Table 4, of the patients with RD, $46.3 \%$ would prefer a Turkish vaccine and $35.5 \%$ would choose the USA/German vaccine. On the other hand, the groups of the general population and healthcare workers would favor the USA/German vaccine (46.8 and $48.4 \%$, respectively) over a Turkish vaccine (26.0 and $16.3 \%$, respectively). Chinese, English and Russian vaccines were among the least favored by all study groups. Approximately 1/5 in all study groups 
Table 5 What are your thoughts on COVID-19 vaccine?

\begin{tabular}{|c|c|c|c|c|}
\hline & $\begin{array}{l}\text { Group } 1 \\
\text { Patients with RD } \\
(n=732)\end{array}$ & $\begin{array}{l}\text { Group } 2 \\
\text { General population } \\
(n=763)\end{array}$ & $\begin{array}{l}\text { Group } 3 \\
\text { Hospital workers } \\
(n=320)\end{array}$ & $P$ \\
\hline I am afraid of side effects, $n(\%)$ & $351(48.0)$ & $330(43.3)$ & $108(33.8)$ & $<0.001 * \dagger \S$ \\
\hline I do not know the scientific results, $n(\%)$ & $217(29.6)$ & $265(34.7)$ & $102(31.9)$ & 0.108 \\
\hline I do not trust, $n(\%)$ & $103(14.1)$ & $158(20.7)$ & $33(10.3)$ & $<0.001 * \S$ \\
\hline I think that it is protective, $n(\%)$ & $189(25.8)$ & $233(30.5)$ & $160(50.0)$ & $<0.001 * \dagger \S$ \\
\hline I do not think that it will protect me, $n(\%)$ & $53(7.2)$ & $59(7.7)$ & $26(8.1)$ & 0.870 \\
\hline $\begin{array}{l}\text { I do not think that COVID-19 is a threat against my } \\
\text { health, } n(\%)\end{array}$ & $30(4.1)$ & $29(3.8)$ & $13(4.1)$ & 0.938 \\
\hline I am allergic to drugs, $n(\%)$ & $22(3.0)$ & $11(1.4)$ & $6(1.9)$ & 0.106 \\
\hline I favor natural or alternative ways of healing, $n(\%)$ & $26(3.6)$ & $23(3.0)$ & $4(1.3)$ & 0.122 \\
\hline I am against all kinds of vaccination, $n(\%)$ & $11(1.5)$ & $16(2.1)$ & $1(0.3)$ & 0.094 \\
\hline
\end{tabular}

$P *$ Group 1 vs Group 2, †: Group 1 vs Group 3, §: Group 2 vs Group 3

revealed that they had no idea on which country's vaccine to prefer if all were to be available.

Opinions on COVID-19 vaccine are shown in Table 5. $48 \%$ of the patients with RD, $43.3 \%$ of the general population, while $33.8 \%$ of the healthcare workers revealed that they were afraid of the side effects $(p<0.001)$. About a third of each study group declared that they do not know the scientific results of the vaccine. Having no trust was another issue which was reported by $14.1 \%$ (RD patients), $20.7 \%$ (general population) and $10.3 \%$ (healthcare workers) $(p<0.001)$. On the other hand, significantly more healthcare workers $(50 \%)$ thought that it will be protective, compared to $25.8 \%$ of the patients with RD and $30.5 \%$ of the general population $(p<0.001)$. Only about less than $10 \%$ of the participants thought that the vaccine would not be protective (RD patients:7.2\%, general population: $7.7 \%$ and healthcare workers: $8.1 \%$ ). Those who declared that they were allergic to drugs, or favor natural/ alternative ways of healing or are against all kinds of vaccines were similarly less than 5\% in all study groups.

\section{Independent predictors of vaccine acceptance (Table 6)}

As shown in Table 6, among 13 probable risk factors (Group, age, gender, education, time spent using social media, COVID-19 related anxiety, comorbid disease, psychiatric disorder, household size, leaving the house for work quite often, diagnosis of COVID-19 in the participant or in a relative or close circle, and death due to COVID-19 among the household or close circle) that were investigated using univariate analysis, 9 (working as a healthcare worker, being $\geq 40$ years of age, being male, having a university degree or more, spending $>1 \mathrm{~h}$ using social media, having a comorbid disease, high scores on COVID-19 related anxiety, leaving the house for work quite often, not having contracted
COVID-19) were found to be associated with a willingness (with a $p$ value of $<0.15$ ). However, of these nine probable risk factors that were entered in the multivariate logistic regression model, five variables (being a healthcare worker, being male, being $\geq 40$ years of age, not having contracted COVID-19 and higher scores on COVID-19 related anxiety) were found to be independent predictors of vaccine acceptance. On the other hand, among patients with RD, only being older than 40 years of age and being male were found to be independently associated with vaccine willingness (data not shown). Significant $P$ values are denoted as 'bold'.

\section{Discussion}

This cross-sectional web-based survey that was done just before the beginning of the mass vaccination program in Turkey, revealed that the majority of the population seems to be reluctant to get vaccinated. Only about one-third of the patients with RD were willing to get vaccinated, which was somewhat comparable to that observed in the general population sample. Similarly, roughly one-third in all study groups thought that vaccination should be mandatory. Being afraid of side effects, being unaware of the scientific results and having no trust were the main concerns related with vaccine.

Whether patients with RD, especially those receiving DMARDs, are at an increased risk for severe COVID-19 infection remains unclear [14]. So far, rheumatic diseases are not listed among the comorbidities that carry increased risk for severe COVID-19 [15]. Patients with rheumatoid arthritis, systemic lupus erythematosus or psoriasis, when analyzed as a combined group, were found to have a slightly increased risk of death from COVID-19 compared to those without these diseases as shown in a meta analysis [16]. Chronic use of glucocorticoids at moderate or high doses 
Table 6 Effect of socio-demographic variables on willingness to get COVID-19 vaccination

\begin{tabular}{|c|c|c|c|c|c|}
\hline & \multicolumn{3}{|c|}{ Willingness to get COVID-19 vaccination } & \multicolumn{2}{|c|}{ Multivariate analysis } \\
\hline & No & Yes & $P$ & $P$ & OR $(95 \% \mathrm{CI})$ \\
\hline \multicolumn{6}{|l|}{ Groups } \\
\hline Patients with RD & $139(39.4)$ & $214(60.6)$ & 0.006 & & 1 \\
\hline Healthcare workers & $67(28.5)$ & $168(71.5)$ & & 0.014 & $1.789(1.125-2.844)$ \\
\hline Population & $178(40.3)$ & $264(59.7)$ & & 0.705 & $0.934(0.654-1.332)$ \\
\hline \multicolumn{6}{|l|}{ Age } \\
\hline$<40$ years & $220(44.1)$ & $279(55.9)$ & $<0.001$ & $<0.001$ & 1 \\
\hline$\geq 40$ years & $164(30.9)$ & $367(69.1)$ & & & $1.762(1.311-2.367)$ \\
\hline \multicolumn{6}{|l|}{ Gender } \\
\hline Female & $268(41.2)$ & $383(58.8)$ & 0.001 & $<0.001$ & 1 \\
\hline Male & $116(30.6)$ & $263(69.4)$ & & & $1.908(1.405-2.591)$ \\
\hline \multicolumn{6}{|l|}{ Education level. } \\
\hline High school or lover & $116(42.5)$ & $157(57.5)$ & 0.038 & 0.058 & 1 \\
\hline University degree or higher & $268(35.4)$ & $489(64.6)$ & & & $1.420(0.988-2.041)$ \\
\hline \multicolumn{6}{|c|}{ Daily spent time using social media } \\
\hline$\leq 1 \mathrm{~h}$ & $106(33.0)$ & $215(67.0)$ & 0.057 & 0.350 & 1 \\
\hline$>1 \mathrm{~h}$ & $278(39.2)$ & $431(60.8)$ & & & $0.865(0.639-1.172)$ \\
\hline \multicolumn{6}{|l|}{ Comorbidity } \\
\hline No & $277(38.9)$ & $435(61.1)$ & 0.107 & 0.569 & 1 \\
\hline Yes & $107(33.6)$ & $211(66.4)$ & & & $1.099(0.794-1.520)$ \\
\hline \multicolumn{6}{|c|}{ Leaving the house for work quite often } \\
\hline No & $221(39.5)$ & $338(60.5)$ & 0.103 & 0.659 & 1 \\
\hline Yes & $163(34.6)$ & $308(65.4)$ & & & $0.930(0.672-1.286)$ \\
\hline \multicolumn{6}{|c|}{ COVID-19 diagnosis in the respondent } \\
\hline Yes & $62(43.7)$ & $80(56.3)$ & 0.080 & 0.034 & 1 \\
\hline No & $317(36.0)$ & $563(64.0)$ & & & $1.520(1.031-2.240)$ \\
\hline COVID-19 anxiety score & $1.3 \pm 2$. & $1.8 \pm 2.8$ & 0.001 & 0.003 & $1.092(1.030-1.157)$ \\
\hline \multicolumn{6}{|c|}{ COVID-19 diagnosis among the household or close circle } \\
\hline No & $137(35.2)$ & $252(64.8)$ & 0.255 & & \\
\hline Yes & $245(38.8)$ & $387(61.2)$ & & - & - \\
\hline \multicolumn{6}{|c|}{ Death due to COVID-19 among the household or close circle } \\
\hline No & $280(37.6)$ & $465(62.4)$ & 0.746 & & \\
\hline Yes & $104(36.5)$ & $181(63.5)$ & & - & - \\
\hline \multicolumn{6}{|l|}{ Psychiatric disease } \\
\hline No & $324(38.0)$ & $528(62.0)$ & 0.278 & & \\
\hline Yes & $60(33.7)$ & $118(66.3)$ & & - & - \\
\hline \multicolumn{6}{|l|}{ Household size } \\
\hline$<4$ person & $226(36.0)$ & $401(64.0)$ & 0.306 & & \\
\hline$\geq 4$ person & $158(39.2)$ & $245(60.8)$ & & - & - \\
\hline
\end{tabular}

Significant $P$ values are given in bold

(equivalent to $>10 \mathrm{mg} / \mathrm{d}$ prednisone) was associated with hospitalization while cytokine inhibitors, were reported to reduce the risk of COVID-19 [16]. It appears that there is no increase in vaccination-related harms in vaccinated patients with RD, and current guidelines recommend vaccinating patients with RD using immuno-modulatory agents, although current evidence from the literature is scarce [17-19]. In the current survey, we observed that the hesitancy rate and attitude towards vaccination among patients with RD were not significantly different than that observed among the general population.

Vaccine hesitancy rate can vary across countries [20-31]. An online survey conducted in Turkey $(n=3936)$ and in the UK ( $n=1088$ ) throughout May 2020 found that COVID-19 vaccine hesitancy was significantly higher in Turkey [20]. In that survey, $31 \%$ of the participants in Turkey and $14 \%$ in 
the UK were unsure about getting vaccinated, and in both countries 3\% rejected to be vaccinated [20]. A survey of 788 U.S. adults showed that $30.7 \%$ of respondents were definitely planning, $29.2 \%$ were probably planning, $18.8 \%$ were undecided, $9.4 \%$ probably not planning and $11.9 \%$ would definitely not planning to receive a future COVID-19 vaccine [21]. Another study reported that $26 \%$ of French adults would not accept a COVID-19 vaccine [22], whereas, in Australia, attitude towards vaccine was more positive, with an acceptance rate of $85.8 \%$ as reported in a survey of 4362 Sidney habitants [23]. Vaccine acceptance rate can also change over time as COVID-19 transmission rates decrease [24]. A longitudinal study in the USA with 7547 participants showed that the willingness to a COVID-19 vaccine declined from $71 \%$ in April 2020 to 53.6\% in October 2020 [24]. The timing of the current survey (done almost immediately preceding vaccine availability) could be related to the significantly low rate of acceptance.

Reluctance to get vaccinated in the current study can be explained by the lack of information about the benefits of vaccination, widespread misinformation about the pandemic, misleading healthcare information, conspiracy theories and mistrust to vaccines in general [20, 24-26, 30, 31]. Additionally, the fact that vaccines have been developed with an unprecedented speed may have caused the public to become more reluctant to accept a vaccine [24]. Online interactive meetings and informative videos on social media can improve willingness to vaccine. On the other hand, the current safety and efficacy data of the vaccine must be shared transparently with the public, as well.

Hesitancy to get vaccinated was reported to be associated with younger age, female gender, lower income, lower level of education and black ethnicity [21, 23, 24, 30-32]. In line with previous reports [21, 23, 24, 30-34], we observed that working in a hospital especially being a physician, being male, being older than 40 years of age, not having contracted COVID-19 and having higher scores on CAS were found to be independently associated with vaccine acceptance. Females were more reluctant to get vaccinated as they tend to inquire more about health-related information (which can mean increased exposure also to misinformation) and they make the majority of health care decisions for their children and other family members [33].

Another important issue in our study was authorization of the emergency use of the vaccine [21]. A previous study showed that EAU appears to reduce vaccine uptake intent [21]. The fact that CoronaVac is still in its third phase of the trial and the low efficacy rates achieved in the interim analyses may have also contributed to public hesitancy in Turkey. Additionally, there is also a general mistrust against Chinese products in Turkey similar to that observed in other parts of the world [32]. In the current survey, Chinese vaccine was reported to be among the least favored by the public. On the other hand, it should be emphasized that $46.3 \%$ of the patients with RD reported that they would have preferred a Turkish vaccine, although such a vaccine is in the very early stages of development. This is important in a way that it shows the degree of trust in their own physicians and healthcare system.

We observed that self-reported willingness to receive vaccination against COVID-19 among healthcare workers differs by hospital roles, with physicians showing the highest acceptance rates. These findings are consistent with previous studies done among the hospital workers [33]. In a recent study, nurses were found to be more likely to delay the vaccination compared to physicians [34]. In another, nearly half or more of nurses and various types of medical personnel were not sure whether the vaccine will work and protect them against COVID-19 [33]. The reluctance of the nurses could be partly explained by this group's being composed of mostly females. Physicians' approval of COVID-19 vaccine is crucial as they are often considered as a trusted public model [33].

We expected the COVID-19 related anxiety would be increased with the second wave of the pandemic. However, we found that the prevalence of dysfunctional anxiety in our patients', as measured by CAS was less than 5\%, which was remarkably lower compared to that found in our previous study [35]. This indicates a fall in the anxiety levels related to COVID-19 in the subsequent periods of the pandemic which could be explained by psychological adaptation to stress and increased resilience.

This study has limitations. Absence of a control group with a distinct inflammatory comorbidity is the main limitation. This cross-sectional survey was conducted in a single health care facility in Istanbul, Turkey. Moreover, there were several demographic and socio-cultural differences between the study groups, therefore our results can not be generalized. As the sampling of our study was voluntary, the possibility of selection bias could not be eliminated. This survey was conducted at a single point in time during a pandemic, in which information, thoughts, decisions and perceptions are rapidly changing. Therefore, individual willingness to get vaccinated may similarly change over time. Finally, the survey was not validated.

\section{Conclusions}

The low rate of vaccine acceptance among patients with $\mathrm{RD}$, as well as the general population sampling is worrying. The so-called 'the pandemic public health paradox' [25] is worth extensive evaluation. Also, the nature and extent of vaccine hesitancy must be evaluated and addressed promptly (25). Healthcare policies should aim to implement 
communication, promote confidence and increase demand for COVID-19 vaccine.

Supplementary Information The online version contains supplementary material available at https://doi.org/10.1007/s00296-021-04841-3.

\section{Acknowledgements The authors thank Ali Cetin Ezber.}

Author contributions All authors contributed to the study conception and design. Material preparation, data collection and analysis were performed by [Emire Seyahi], [Burc Cagri Poyraz], [Necdet Sut], [Berna Yurttas] and [Vedat Hamuryudan]. The first draft of the manuscript was written by [Emire Seyahi, Berna Yurttas and Burc Cagri Poyraz] and all authors commented on previous versions of the manuscript. All authors read and approved the final manuscript.

Funding The authors have not received any financial support.

\section{Declarations}

Conflict of interest Berna Yurttas, Burc Cagri Poyraz, Necdet Sut,Ayse Ozdede, Mert Oztas, Serdal Ugurlu, Fehmi Tabak, Vedat Hamuryudan and Emire Seyahi declare that they have no conflict of interest.

\section{References}

1. https://covid19.who.int/. Accessed 12 Feb 2021

2. Randolph HE, Barreiro LB (2020) Herd Immunity: understanding COVID-19. Immunity 52(5):737-741. https://doi.org/10.1016/j. immuni.2020.04.012 (PMID:32433946;PMCID:PMC7236739)

3. Rawat K, Kumari P, Saha L (2021) COVID-19 vaccine: a recent update in pipeline vaccines, their design and development strategies. Eur J Pharmacol 892:173751. https://doi.org/10.1016/j. ejphar.2020.173751 (Epub 2020 Nov 25. PMID: 33245898; PMCID: PMC7685956)

4. https://covid.who.int/region/euro/country/tr. Accessed 16 Feb 2021

5. Zhang Y, Zeng G, Pan H, Li C, Hu Y, Chu K, Han W, Chen Z, Tang R, Yin W, Chen X, Hu Y, Liu X, Jiang C, Li J, Yang M, Song Y, Wang X, Gao Q, Zhu F (2021) Safety, tolerability, and immunogenicity of an inactivated SARS-CoV-2 vaccine in healthy adults aged 18-59 years: a randomised, double-blind, placebocontrolled, phase 1/2 clinical trial. Lancet Infect Dis. 21(2):181192. https://doi.org/10.1016/S1473-3099(20)30843-4 (Epub 2020 Nov 17. PMID: 33217362; PMCID: PMC7832443)

6. Wu Z, Hu Y, Xu M, Chen Z, Yang W, Jiang Z, Li M, Jin H, Cui G, Chen P, Wang L, Zhao G, Ding Y, Zhao Y, Yin W (2021) Safety, tolerability, and immunogenicity of an inactivated SARS-CoV-2 vaccine (Corona $\mathrm{Vac}$ ) in healthy adults aged 60 years and older: a randomised, double-blind, placebo-controlled, phase $1 / 2$ clinical trial. Lancet Infect Dis. https://doi.org/10.1016/S1473-3099(20) 30987-7 (Epub ahead of print. PMID: 33548194)

7. https://www.bloomberg.com/news/articles/2020-12-18/turkey-tobegin-sinovac-covid-vaccinations-before-trials-over. Accessed 20 Feb 2021

8. https://www.aa.com.tr/en/turkey/turkey-grants-approval-for-chine se-covid-19-vaccine/2108980. Accessed 20 Feb 2021

9. https://edition.cnn.com/world/live-news/coronavirus-pandemicvaccine-updates-01-13-21/h_958eb4067c8d0dea76f631a2d96ea9 4b. Accessed 20 Feb 2021
10. Gaur PS, Zimba O, Agarwal V, Gupta L (2020) Reporting survey based studies-a primer for authors. J Korean Med Sci 35(45):e398. https://doi.org/10.3346/jkms.2020.35.e398

11. Lee SA, Mathis AA, Jobe MC, Pappalardo EA (2020) Clinically significant fear and anxiety of COVID-19: a psychometric examination of the Coronavirus Anxiety Scale. Psychiatry Res. 290:113112. https://doi.org/10.1016/j.psychres.2020.113112

12. Evren C, Evren B, Dalbudak E, Topcu M, Kutlu N (2020) Measuring anxiety related to COVID-19: a Turkish validation study of the Coronavirus Anxiety Scale. Death Stud. https://doi.org/10. 1080/07481187.2020.1774969 (Epub ahead of print. PMID: 32490730)

13. Lee SA (2020) Coronavirus Anxiety Scale: a brief mental health screener for COVID-19 related anxiety. Death Stud 44(7):393401. https://doi.org/10.1080/07481187.2020.174848116 (PMID: 32299304)

14. Grainger R, Machado PM, Robinson PC (2020) Novel coronavirus disease-2019 (COVID-19) in people with rheumatic disease: epidemiology and outcomes. Best Pract Res Clin Rheumatol. 23:101657. https://doi.org/10.1016/j.berh.2020.101657 (Epub ahead of print. PMID: 33468418; PMCID: PMC7756169)

15. Dorjee K, Kim H, Bonomo E, Dolma R (2020) Prevalence and predictors of death and severe disease in patients hospitalized due to COVID-19: a comprehensive systematic review and meta-analysis of 77 studies and 38,000 patients. PLoS ONE 15(12):e0243191. https://doi.org/10.1371/journal.pone.0243191 (PMID:33284825; PMCID:PMC7721151)

16. Hyrich KL, Machado PM (2021) Rheumatic disease and COVID19: epidemiology and outcomes. Nat Rev Rheumatol 17(2):71-72. https://doi.org/10.1038/s41584-020-00562-2 (PMID:33339986; PMCID:PMC7747184)

17. https://www.rheumatology.org/Portals/0/Files/COVID-19-Vacci ne-Clinical-Guidance-Rheumatic-Diseases-Summary.pdf. Accessed $20 \mathrm{Feb} 2021$

18. Bijlsma JW (2021) EULAR December 2020 View points on SARS-CoV-2 vaccination in patients with RMDs. Ann Rheum Dis. https://doi.org/10.1136/annrheumdis-2020-219773 (Epub ahead of print. PMID: 33563595)

19. Schulze-Koops H, Krüger K, Hoyer BF, Leipe J, Iking-Konert C, Specker C, Commission for Pharmacotherapy and the Board of Directors of the German Society for Rheumatology (2021) Updated recommendations of the German Society for Rheumatology for the care of patients with inflammatory rheumatic diseases in times of SARS-CoV-2 - methodology, key messages and justifying information. Rheumatology (Oxford). https://doi.org/ 10.1093/rheumatology/keab072 (Epub ahead of print. PMID: 33502500)

20. Salali GD, Uysal MS (2020) COVID-19 vaccine hesitancy is associated with beliefs on the origin of the novel coronavirus in the UK and Turkey. Psychol Med 19:1-3. https://doi.org/10.1017/ S0033291720004067 (Epub ahead of print. PMID: 33070804; PMCID: PMC7609204)

21. Guidry JPD, Laestadius LI, Vraga EK, Miller CA, Perrin PB, Burton CW, Ryan M, Fuemmeler BF, Carlyle KE (2021) Willingness to get the COVID-19 vaccine with and without emergency use authorization. Am J Infect Control 49(2):137-142. https:// doi.org/10.1016/j.ajic.2020.11.018 (Epub 2020 Nov 20. PMID: 33227323; PMCID: PMC767)

22. Ward JK, Alleaume C, Peretti-Watel P, COCONEL Group (2020) The French public's attitudes to a future COVID-19 vaccine: the politicization of a public health issue. Soc Sci Med 265:113414. https://doi.org/10.1016/j.socscimed.2020.113414 (Epub 2020 Oct 6. PMID: 33038683; PMCID: PMC7537647)

23. Dodd RH, Cvejic E, Bonner C, Pickles K, McCaffery KJ (2020) Sydney Health Literacy Lab COVID-19 group. Willingness to vaccinate against COVID-19 in Australia. Lancet Infect Dis. 
https://doi.org/10.1016/S1473-3099(20)30559-4 (Epub ahead of print. PMID: 32619436; PMCID: PMC7326391)

24. Daly M, Robinson E (2020) Willingness to vaccinate against COVID-19 in the US: longitudinal evidence from a nationally representative sample of adults from April-October 2020. medRxiv [Preprint]. https://doi.org/10.1101/2020.11.27.20239970 (PMID: 33269354; PMCID: PMC7709168)

25. Fadda M, Albanese E, Suggs LS (2020) When a COVID-19 vaccine is ready, will we all be ready for it? Int J Public Health 65(6):711-712. https://doi.org/10.1007/s00038-020-01404-4 (Epub 2020 Jun 11. PMID: 32529534; PMCID: PMC7288619)

26. Alley SJ, Stanton R, Browne M, To QG, Khalesi S, Williams SL, Thwaite TL, Fenning AS, Vandelanotte C (2021) As the pandemic progresses, how does willingness to vaccinate against cOVID19 evolve? Int J Environ Res Public Health 18(2):797. https:// doi.org/10.3390/ijerph18020797 (PMID:33477825;PMCID: PMC7832839)

27. Alqudeimat Y, Alenezi D, AlHajri B, Alfouzan H, Almokhaizeem Z, Altamimi S, Almansouri W, Alzalzalah S, Ziyab A (2021) Acceptance of a COVID-19 vaccine and its related determinants among the general adult population in Kuwait. Med Princ Pract. https://doi.org/10.1159/000514636 (Epub ahead of print. PMID: 33486492)

28. Al-Mohaithef M, Padhi BK (2020) Determinants of COVID-19 vaccine acceptance in Saudi Arabia: a web-based national survey. J Multidiscip Healthc 20(13):1657-1663. https://doi.org/10.2147/ JMDH.S276771 (PMID:33262600;PMCID:PMC7686470)

29. Palamenghi L, Barello S, Boccia S, Graffigna G (2020) Mistrust in biomedical research and vaccine hesitancy: the forefront challenge in the battle against COVID-19 in Italy. Eur J Epidemiol 35(8):785-788. https://doi.org/10.1007/s10654-020-00675-8 (Epub 2020 Aug 17. PMID: 32808095; PMCID: PMC7431109)

30. Reiter PL, Pennell ML, Katz ML (2020) Acceptability of a COVID-19 vaccine among adults in the United States: How many people would get vaccinated? Vaccine 38(42):6500-6507. https://doi.org/10.1016/j.vaccine.2020.08.043 (Epub 2020 Aug 20. PMID: 32863069; PMCID: PMC7440153)
31. Freeman D, Loe BS, Chadwick A, Vaccari C, Waite F, Rosebrock L, Jenner L, Petit A, Lewandowsky S, Vanderslott S, Innocenti S, Larkin M, Giubilini A, Yu LM, McShane H, Pollard AJ, Lambe S (2020) COVID-19 vaccine hesitancy in the UK: the Oxford coronavirus explanations, attitudes, and narratives survey (Oceans) II. Psychol Med 11:1-15. https://doi.org/10.1017/S003329172 0005188 (Epub ahead of print. PMID: 33305716; PMCID: PMC7804077)

32. Kreps S, Prasad S, Brownstein JS, Hswen Y, Garibaldi BT, Zhang B, Kriner DL (2020) Factors associated with US adults' likelihood of accepting COVID-19 vaccination. JAMA Netw Open 3(10):e2025594. https://doi.org/10.1001/jamanetworkopen.2020. 25594 (Erratum.In:JAMANetwOpen.2020Nov2;3(11):e20306 49.PMID:33079199;PMCID:PMC7576409)

33. Shaw J, Stewart T, Anderson KB, Hanley S, Thomas SJ, Salmon DA, Morley C (2021) Assessment of U.S. health care personnel (HCP) attitudes towards COVID-19 vaccination in a large university health care system. Clin Infect Dis. https://doi.org/10.1093/ $\mathrm{cid} / \mathrm{ciab054}$ (Epub ahead of print. PMID: 33491049)

34. Gadoth A, Halbrook M, Martin-Blais R, Gray A, Tobin NH, Ferbas KG, Aldrovandi GM, Rimoin AW (2021) Cross-sectional Assessment of COVID-19 vaccine acceptance among health care workers in Los Angeles. Ann Intern Med. https://doi.org/10.7326/ M20-7580 (Epub ahead of print. PMID: 33556267)

35. Seyahi E, Poyraz BC, Sut N, Akdogan S, Hamuryudan V (2020) The psychological state and changes in the routine of the patients with rheumatic diseases during the coronavirus disease (COVID19) outbreak in Turkey: a web-based cross-sectional survey. Rheumatol Int 40(8):1229-1238. https://doi.org/10.1007/s00296020-04626-0 (Epub 2020 Jun 22. PMID: 32572609; PMCID: PMC7306572)

Publisher's Note Springer Nature remains neutral with regard to jurisdictional claims in published maps and institutional affiliations.

\section{Authors and Affiliations}

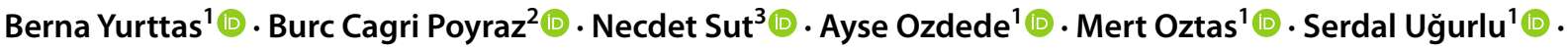 Fehmi Tabak $^{4}$ (D) . Vedat Hamuryudan ${ }^{1}$ (i) $\cdot$ Emire Seyahi $^{1}$ (i)}

Berna Yurttas

bernayurttasmd@gmail.com

Burc Cagri Poyraz

bcpoyraz@yahoo.com

Necdet Sut

necdetsut@yahoo.com

Ayse Ozdede

ayseozdede@hotmail.com

Mert Oztas

dr.mertoztas@gmail.com

Serdal Uğurlu

serdalugurlu@gmail.com

Fehmi Tabak

ftabak@istanbul.edu.tr
Vedat Hamuryudan

vhamuryudan@yahoo.com

1 Cerrahpasa Medical Faculty, Department of Internal Medicine, Division of Rheumatology, Istanbul UniversityCerrahpasa, Istanbul, Turkey

2 Cerrahpasa Medical Faculty, Department of Psychiatry, Division of Geriatric Psychiatry, Istanbul University-Cerrahpasa, Istanbul, Turkey

3 Department of Biostatistics and Medical Informatics, Trakya University Medical Faculty, Edirne, Turkey

4 Cerrahpasa Medical Faculty, Department of Infectious Disease and Clinical Microbiology, Istanbul University-Cerrahpasa, Istanbul, Turkey 